\title{
Non-Classic Disorder of Adrenal Steroidogenesis and Clinical Dilemmas in 21-Hydroxylase Deficiency Combined with Backdoor Androgen Pathway. Mini-Review and Case Report
}

\author{
Marta Sumińska ${ }^{1, *(1)}$, Klaudia Bogusz-Górna ${ }^{1}$, Dominika Wegner ${ }^{1}$ and Marta Fichna ${ }^{2}(\mathbb{D}$ \\ 1 Department of Pediatric Diabetes and Obesity, Poznan University of Medical Sciences, \\ 60-527 Poznan, Poland; kl.bogusz@gmail.com (K.B.-G.); dominika.wegner@op.pl (D.W.) \\ 2 Department of Endocrinology, Metabolism and Internal Medicine, Poznan University of Medical Sciences, \\ 60-653 Poznan, Poland; mfichna@ump.edu.pl \\ * Correspondence: marta_suminska@o2.pl
}

Received: 3 June 2020; Accepted: 28 June 2020; Published: 29 June 2020

\begin{abstract}
Congenital adrenal hyperplasia (CAH) is the most common cause of primary adrenal insufficiency in children and adolescents. It comprises several clinical entities associated with mutations in genes, encoding enzymes involved in cortisol biosynthesis. The mutations lead to considerable (non-classic form) to almost complete (classic form) inhibition of enzymatic activity, reflected by different phenotypes and relevant biochemical alterations. Up to $95 \%$ cases of CAH are due to mutations in CYP21A2 gene and subsequent $21 \alpha$-hydroxylase deficiency, characterized by impaired cortisol synthesis and adrenal androgen excess. In the past two decades an alternative ("backdoor") pathway of androgens' synthesis in which $5 \alpha$-androstanediol, a precursor of the $5 \alpha$-dihydrotestosterone, is produced from $17 \alpha$-hydroxyprogesterone, with intermediate products $3 \alpha, 5 \alpha-17 \mathrm{OHP}$ and androsterone, in the sequence and with roundabout of testosterone as an intermediate, was reported in some studies. This pathway is not always considered in the clinical assessment of patients with hyperandrogenism. The article describes the case of a 17-year-old female patient with menstrual disorders and androgenization (persistent acne, advanced hirsutism). Her serum dehydroepiandrosterone sulfate and testosterone were only slightly elevated, along with particularly high values for $5 \alpha$-dihydrotestosterone. In $24 \mathrm{~h}$ urine collection, an increased excretion of 16 $\alpha$-OHDHEA-a dehydroepiandrosterone metabolite-and pregnanetriolone-a $17 \alpha$-hydroxyprogesterone metabolite-were observed. The investigations that we undertook provided evidence that the girl suffered from non-classic $21 \alpha$-hydroxylase deficiency with consequent enhancement of the androgen "backdoor" pathway in adrenals, peripheral tissues or both, using adrenal origin precursors. The paper presents diagnostic dilemmas and strategies to differentiate between various reasons for female hyperandrogenism, especially in childhood and adolescence.
\end{abstract}

Keywords: non-classic congenital adrenal hyperplasia; 21-hydroxylase deficiency; backdoor androgen pathway; 16 $\alpha$-hydroxydehydroepiandrosterone (16 $\alpha$-OHDHEA); pregnanetriolone (PTN)

\section{Introduction}

\subsection{Relationship between Adrenal Cortex Structure and Function}

The adrenal glands have a complex structure and function. They consist of an outer adrenal cortex with three distinguishable zones and an inner adrenal medulla, characterized by centripetal blood flow. 
The cortex is the place of complex and multistage processes of steroidogenesis, which initially proceeds along a common pathway and then, depending on the zone, leads to production of mineralocorticoids (zona glomerulosa), glucocorticoids (zona fasciculata) and adrenal androgens (zona reticularis) synthesis. The activity of zona glomerulosa enzymes is modulated by the renin-angiotensin-aldosterone system, while two other main pathways remain under control of the hypothalamic-pituitary-adrenal (HPA) axis. Adrenocorticotropic hormone (ACTH) stimulates the secretion of cortisol (z. fasciculata) and adrenal androgens (z. reticularis) [1]. However, the negative feedback response relies uniquely upon suppressive effect of circulating cortisol on corticotropin-releasing hormone (CRH) and ACTH release, whereas adrenal androgens cannot exert similar influences on the HPA axis [2]. Moreover, the vascular system in the adrenal gland enables it to supply steroidogenic cells in zona reticularis with high local concentrations of precursor steroids (e.g., $17 \alpha$-hydroxyprogesterone, 17OHP) from zona fasciculata, and this influx is further enhanced if there are enzymatic deficiencies in the glucocorticoid pathway [3]. This process illustrates the ultra-short endocrine (blood transport is engaged), paracrine (both zones are neighboring tissues) or even intracrine mechanisms (precursor steroids from zona fasciculata are processed to androgens inside the cells of zona reticularis) implicated in adrenal steroidogenesis.

\subsection{Congenital Adrenal Hyperplasia and Androgen Biosynthesis}

Congenital adrenal hyperplasia (CAH) is the most common cause of primary adrenal insufficiency in children and adolescents [1]. It comprises several clinical entities associated with mutations in distinct genes, which encode enzymes involved in cortisol biosynthesis. The ensuing enzymatic defects, inherited in an autosomal recessive manner, lead to considerable reduction or almost complete inhibition of their activity. The result of these disorders is cortisol deficiency coexisting with excess or deficiency of mineralocorticoids and adrenal androgens. Clinical consequences of these mutations are reflected by different phenotypes and relevant changes in the laboratory tests, depending on specific enzyme affected and the degree of its dysfunction (almost total deficit results in classic disease form, while partially limited enzymatic activity leads to non-classic forms). Up to $95 \%$ of CAH cases are due to mutations in CYP21A2 gene and subsequent deficit of $21 \alpha$-hydroxylase [4,5]. Less common reasons comprise mutations of CYP11B1 which result in $11 \beta$-hydroxylase deficiency ( $3-4 \%$ of CAH cases) and other $(1-2 \%)$ very rare enzymatic blocks $[5,6]$.

Since the core problem in classic CAH is cortisol shortage, the leading aim of therapy is its substitution as well as suppression of the hypothalamus (CRH) and pituitary gland (ACTH) with exogenous glucocorticoid in order to achieve inhibition of excess androgen production $[7,8]$. The first-choice drug is usually hydrocortisone, identical to natural cortisol, at a dose of $10-18 \mathrm{mg} / \mathrm{m}^{2}$ of the body surface divided into three (four) doses per day [9,10]. However, in non-classic CAH forms, where levels of endogenous cortisol remain normal and values of other metabolites are only moderately elevated, the inclusion of suppressive treatment to bring the elevated CRH and ACTH levels down may generate adverse effects due to supra-physiological dosing of glucocorticoids. On the other hand, each unblocked ACTH burst will result in transient excess of androgen secretion. Therefore, proper and well-balanced treatment is of critical importance in this condition, and this is only possible with an accurate diagnosis. In non-classic, subtle disorders of adrenal steroidogenesis diagnostic procedures are often bothersome and require meticulous analyses. Even if many of these disorders start early in childhood, their clinical manifestation is very mild, but usually exacerbates later on, e.g., at puberty, leading to overt symptoms in adolescent girls and adult women, who may present with disturbed ovarian function.

In the past two decades an alternative ("backdoor") pathway of androgens' syntheses in which $5 \alpha$-androstanediol, precursor of the $5 \alpha$-dihydrotestosterone (DHT), is produced from 17OHP, with intermediate products $3 \alpha, 5 \alpha-17 \mathrm{OHP}$ and androsterone, in the sequence and with roundabout of testosterone as an intermediate product, was reported in some studies (Figure 1) [11-13]. Such a pathway is not always taken into account in the clinical assessment of patients with hyperandrogenism, hence this may be a source of diagnostic pitfalls and confusion. 


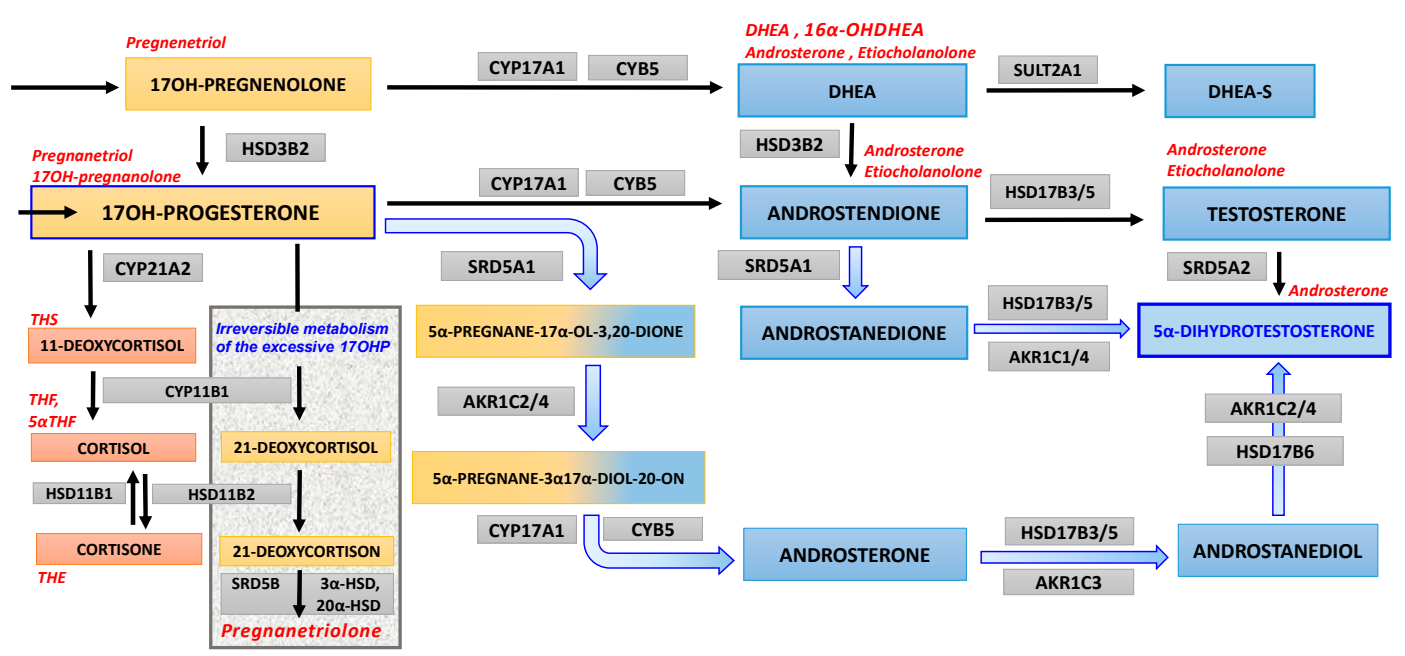

Figure 1. Androgen "backdoor" steroidogenesis pathway. The orange boxes bear the names of the steroid precursors at early stages of steroidogenesis and for $17 \mathrm{OHP}$ and its derivatives; reddish boxes for the cortisol pathway and its metabolite; blue areas (and mixed orange/blue) are background for androgens and their precursors; and finally gray boxes bear names of enzymes, which are involved in consecutive steps of steroidogenesis. The bluish arrows depict steps of the androgen backdoor pathway. The left side of the figure presents a few steps of steroidogenesis leading to cortisol synthesis (steroidogenesis beginning from cholesterol towards mineralocorticoid pathway is omitted), which are adjacent the rectangle area displaying the irreversible pathway from $17 \mathrm{OH}$-progesterone to pregnanetriolone, a marker of adrenal origin of 17OHP. The upper row (from $17 \mathrm{OH}$-pregnenolone) presents canonical steroidogenic steps to dehydroepiandrosterone (and its sulfate), which initiate progression of so-called classic androgen pathways toward testosterone and thereafter, to $5 \alpha$-dihydrotestosterone. The main substrate appears to be $17 \mathrm{OH}$-progesterone, which fuels (broad bluish arrows) the "androgen backdoor pathway" and eventually reaches $5 \alpha$-dihydrotestosterone with omission of testosterone as an intermediate step. The abbreviations of the enzymes involved in each step are displayed in gray boxes: AKR1C1/4 aldo-keto reductase

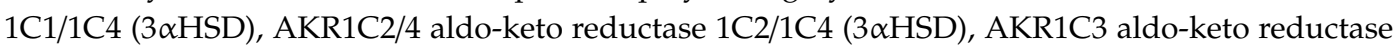
1C3 (17 $\beta$-hydroxysteroid dehydrogenase type 5), CYB5 cytochrome b5, CYP11B1 cytochrome P450 11 $\beta$-hydroxylase, CYP17A1 cytochrome P450 17 $\alpha$-hydroxylase/17,20-lyase, CYP21A2 cytochrome P450 21 $\alpha$-hydroxylase, HSD11B1 11ß-hydroxysteroid dehydrogenase type 1 (mainly reductase 11BHSD), HSD11B2 11ß-hydroxysteroid dehydrogenase type 2 (mainly oxidase 11BHSD), HSD3B2 3b-hydroxysteroid dehydrogenase type 2, HSD17B3/5 17 $\beta$-hydroxysteroid dehydrogenase type 3/type 5, HSD17B6 17 $\beta$-hydroxysteroid dehydrogenase type 6, 3 $\alpha$ HSD $3 \alpha$-hydroxysteroid dehydrogenase, $20 \alpha$ HSD $20 \alpha$-hydroxysteroid dehydrogenase, SRD5A1 steroid $5 \alpha$-reductase type 1, SRD5A2 steroid $5 \alpha$-reductase type 2, SRD5B steroid 5 $\beta$-reductase (AKR1D1 5b-reductase), SULT2A1 sulfotransferase 2A1 (DHEA sulfotransferase). Steroid metabolites usually estimated in urines are indicated in red letters close to their steroid precursors.

\section{Case Report}

A 17-year-old girl (menarche at $12 \mathrm{y}$ ) presented with oligomenorrhea (menstrual cycles of 40-75 days) and hyperandrogenism observed for the last few years, since puberty. She suffered from persistent, severe acne, oily skin and hirsutism (modified Ferriman-Gallway score 11). Her weight was $57 \mathrm{~kg}$, height $168 \mathrm{~cm}$ and body mass index (BMI) $20.2 \mathrm{~kg} / \mathrm{m}^{2}$.

The patient was admitted to the Children's Hospital at Poznan University of Medical Sciences. Written consent for routine diagnostic and treatment procedures is always taken on admission, together with consent for the use of all diagnostic or treatment results for scientific analysis and anonymous publication. Informed consent was obtained from the patient, aged 17 years old and from her legal representative, i.e., her mother. The approval of the Ethics Committee is not required for case reports as long as there is no experimental or out of label procedures applied. In the described case only 
routine procedures were performed and the value of our study relies upon meticulous analysis of all collected data.

Five months earlier she had been admitted into a gynecological ward where the diagnostic tests revealed slightly elevated levels of prolactin, $27.24 \mathrm{ng} / \mathrm{mL}$ (reference range: 4.79-23.30), and dehydroepiandrosterone sulfate (DHEA-S), $13.44 \mu \mathrm{mol} / \mathrm{L}$ (reference range: 1.77-9.99). Total testosterone $(\mathrm{T})$ was $2.60 \mathrm{nmol} / \mathrm{L}$ (reference range: $0.2-2.80$ ) and sex hormone binding globulin (SHBG), $103.1 \mathrm{nmol} / \mathrm{L}$ (reference range: 26.1-110.0). Free androgen index (FAI) was 2.5, and bioavailable testosterone was $0.50 \mathrm{nmol} / \mathrm{L}$, i.e., $19.0 \%$. In an abdominal ultrasound, the uterus size was estimated as $38 \times 25 \mathrm{~mm}$, endometrium $6 \mathrm{~mm}$, while ovaries were not described at all. According to the patient's statement, gynecological examination was not performed at that time. In an oral glucose tolerance test (OGTT) the fasting glucose was $106 \mathrm{mg} / \mathrm{dL}$ and in the 120th minute $145 \mathrm{mg} / \mathrm{dL}$; while fasting insulin $14 \mathrm{IU} / \mathrm{mL}$ and $73 \mathrm{IU} / \mathrm{mL}$ at $120 \mathrm{~min}$ post glucose load. Based on these results, insulin resistance was diagnosed (homeostatic model assessment of insulin resistance, HOMA-IR 3.66) with borderline glycemia for impaired tolerance. Treatment with metformin was recommended; however, the patient has never started this therapy.

A few months later her hormonal diagnostic was extended in the pediatric endocrinology ward. The patient supplied her $24 \mathrm{~h}$ urine collection completed in the morning of admission (4th/5th day of follicular phase), which was sent for steroid profile evaluation. Thyroid function tests, including thyroid-stimulating hormone (TSH), free thyroxine (fT4) and free triiodothyronine (fT3) were all within the reference range. Other hormonal tests performed on the 6th day of the menstrual cycle revealed serum DHEA-S $11.39 \mu \mathrm{mol} / \mathrm{L}$, i.e., close to the upper limit of normal, the luteinizing hormone/follicle stimulating hormone (LH/FSH) ratio $9.8 / 6.3 \mathrm{mIU} / \mathrm{mL}$, i.e., only slightly shifted towards $\mathrm{LH}$, with the estradiol (E2) level $38 \mathrm{pg} / \mathrm{mL}$, i.e., at the lower limit of the reference range. Morning plasma ACTH was $84.9 \mathrm{pg} / \mathrm{mL}$ (reference range up to $60 \mathrm{pg} / \mathrm{mL}$ ) (Table 1).

Table 1. Results of basic hormonal serum estimations.

\begin{tabular}{ccc}
\hline Hormones & Value & Reference Values \\
\hline $\mathrm{LH}^{1},(\mathrm{mIU} / \mathrm{mL})$ & 9.80 & $1.80-11.78$ \\
$\mathrm{FSH}^{2},(\mathrm{mIU} / \mathrm{mL})$ & 6.30 & $3.00-8.10$ \\
$\mathrm{E}^{3},(\mathrm{pg} / \mathrm{mL})$ & 38.00 & $21.00-251.00$ \\
$\mathrm{ACTH}^{4},(\mathrm{pg} / \mathrm{mL})$ & 84.90 & $10.00-60.00$ \\
$\mathrm{~T}^{5},(\mathrm{nmol} / \mathrm{L})$ & 2.26 & $0.38-2.74$ \\
$\mathrm{DHEA}^{6}{ }^{6},(\mu \mathrm{mol} / \mathrm{L})$ & 11.39 & $3.17-14.39$ \\
\hline
\end{tabular}

${ }^{1}$ LH luteinizing hormone; ${ }^{2}$ FSH follicle stimulating hormone; ${ }^{3}$ E2 estradiol; ${ }^{4}$ ACTH adrenocorticotropic hormone;

${ }^{5} \mathrm{~T}$ testosterone and ${ }^{6}$ DHEA-S dehydroepiandrosterone sulfate.

The OGTT was repeated with simultaneous estimations of frequently sampled glycemia, serum insulin and C-peptide levels. Its results were within the range of reference (HOMA-IR 1.58) and excluded glycemic-insulin disturbances in the patient (Table 2).

Standard adrenocortical stimulation (on 7th day of cycle) with $250 \mu \mathrm{g}$ intravenous Synacthen (an $\mathrm{ACTH}_{1-24}$ analogue) revealed normal secretory reaction of cortisol, 17OHP and androstenedione (ANDR) (Table 3).

Table 2. Results of the oral glucose tolerance test (75 g glucose load).

\begin{tabular}{cccc}
\hline Time $(\mathbf{m i n})$ & Glucose $(\mathbf{m g} / \mathbf{d L})$ & Insulin $(\mu \mathbf{U} / \mathbf{m L})$ & C-Peptide $(\mathbf{p m o l} / \mathbf{m L})$ \\
\hline $0^{\prime}$ & 84 & 7.60 & 0.59 \\
$30^{\prime}$ & 160 & 45.50 & - \\
$60^{\prime}$ & 146 & 53.80 & 3.57 \\
$90^{\prime}$ & 111 & 45.70 & - \\
$120^{\prime}$ & 107 & 38.50 & 3.02 \\
$150^{\prime}$ & 111 & 32.70 & - \\
\hline
\end{tabular}


Table 3. Results of intravenous stimulation test with Synacthen.

\begin{tabular}{cccc}
\hline Time $(\mathbf{m i n})$ & $\mathbf{F}^{\mathbf{1}}(\mathbf{n g} / \mathbf{m L})$ & $\mathbf{1 7 O H P}^{\mathbf{2}}(\mathbf{n g} / \mathbf{m L})$ & ANDR $^{\mathbf{3}}(\mathbf{n g} / \mathbf{m L})$ \\
\hline $0^{\prime}$ & 212.00 & 1.66 & 3.00 \\
$60^{\prime}$ & 272.00 & 2.29 & 3.10 \\
$120^{\prime}$ & 261.00 & 2.38 & 3.59 \\
\hline
\end{tabular}

${ }^{1} \mathrm{~F}$ cortisol; ${ }^{2}$ 17OHP $17 \alpha$-hydroxyprogesterone; ${ }^{3}$ ANDR androstenedione.

The results of steroid metabolites estimation in $24 \mathrm{~h}$ urine collection demonstrated an increased amount of $16 \alpha$-OHDHEA $(610.2 \mu \mathrm{g} / 24 \mathrm{~h})$ - a dehydroepiandrosterone metabolite—and a marked increase in excretion of pregnanetriolone (PTN, $142.5 \mu \mathrm{g} / 24 \mathrm{~h}$ ) (Table 4).

Table 4. Steroid profile in 24-h urine collection (gas chromatography mass spectrometry, GC-MS).

\begin{tabular}{|c|c|c|}
\hline Steroid Metabolites & Results $(\mu \mathrm{g} / 24 \mathrm{~h})$ & Reference Range Values \\
\hline AN (androsterone) & 2102.5 & $(710-3140)$ \\
\hline ET (etiocholanolone) & 1994.7 & $(380-2590)$ \\
\hline 11-OAN/ET (11-ketoandrosterone/etiocholanolone) & 103.5 & \\
\hline 11-OHAN (11-hydroxy-androsterone) & 271.6 & $(180-912)$ \\
\hline 11-OHET (11-hydroxy-etiocholanolone) & 55.0 & $(54-750)$ \\
\hline ET/AN & 0.9 & \\
\hline DHEA (dehydroepiandrosterone) & 438.2 & $(73-559)$ \\
\hline 5-AND (5-androstenediol) & 131.5 & $(16-180)$ \\
\hline 16 $\alpha$-OHDHEA (16alpha-hydroxy-DHEA) & 610.2 & $(50-490)$ \\
\hline An-3-ol (5-androstenetriol) & 357.5 & $(130-610)$ \\
\hline 5-PT (5-pregnenetriol) & 175.9 & $(80-390)$ \\
\hline 16-OHPN (16alpha-hydroxy-pregnenolone) & 0.0 & \\
\hline 17-OHPN (5beta) (17-hydroxy-pregnanolone) & 124.9 & $(25-208)$ \\
\hline 17-OHPN (5alpha) (17-hydroxy-pregnanolone) & 6.1 & $(0.5-9)$ \\
\hline PT (pregnanetriol) & 385.0 & $(185-885)$ \\
\hline PTN (pregnanetriolone) & 142.5 & $(10-50)$ \\
\hline PD (pregnanediol) & 227.2 & $<900$ \\
\hline E1 (estrone) & 3.7 & $(0-52)$ \\
\hline E2 (estradiol) & 1.4 & $(0-15)$ \\
\hline E3 (estriol) & 4.0 & $(1-30)$ \\
\hline THS (tetrahydro-11-deoxycortisol) & 36.2 & $(20-72)$ \\
\hline THDOC (tetrahydro-11-deoxycorticosterone) & 4.9 & $(<16)$ \\
\hline THA (tetrahydro-11-dehydrocorticosterone) & 83.2 & $(50-260)$ \\
\hline allo-THA (allo-tetrahydro-11-dehydrocorticosterone) & 24.6 & \\
\hline THB (tetrahydro-corticosterone) & 66.2 & $(20-256)$ \\
\hline allo-THB (allo-tetrahydro-corticosterone) & 79.0 & $(78-543)$ \\
\hline THAldo (tetrahydro-aldosterone) & 25.6 & $(7-51)$ \\
\hline THE (tetrahydro-cortisone) & 1995.6 & $(585-3960)$ \\
\hline THF (tetrahydro-cortisol) & 771.4 & $(315-2060)$ \\
\hline allo-THF (allo-tetrahydro-cortisol) & 425.0 & $(420-2660)$ \\
\hline THF/allo-THF & 2.2 & \\
\hline THF+allo-THF/THF & 0.6 & $(0.55-1.2)$ \\
\hline a-CTN (alpha-cortolone) & 1065.8 & $(360-1420)$ \\
\hline b-CTN (beta-cortolone) & 273.8 & $(75-925)$ \\
\hline a-CT (alpha-cortol) & 154.7 & $(30-800)$ \\
\hline b-CT (beta-cortol) & 110.7 & $(60-300)$ \\
\hline E (cortisone) & 70.3 & $(17-115)$ \\
\hline $\mathrm{F}($ cortisol $)$ & 46.8 & $(9-52)$ \\
\hline F/E (cortisol/cortisone) & 0.7 & $(0.35-0.75)$ \\
\hline 6b-OHF (6beta-hydrocortisol) & 0.0 & \\
\hline 20a-DHF (20alfa/beta-dihydrocortisol) & 0.0 & \\
\hline
\end{tabular}

In the table, bold was used to emphasize that both compounds do not fall within the reference range values, which is clinically relevant.

In conclusion to their analysis, the steroid laboratory suggested excluding $\mathrm{CAH}$ in this patient. However, according to the clinical endocrinologist, the selective imbalance of excreted steroid 
metabolites was probably due to a mild restriction of $21 \alpha$-hydroxylase (elevated PTN was suggestive of excess 17OHP). The contribution of the alternative pathway leading to enhanced production of DHT, with omission of $\mathrm{T}$, was also suspected because of the discrepancy between severe skin symptoms and formerly reported normal serum testosterone level.

In the next step, a 3-day dexamethasone $(0.5 \mathrm{mg}$ orally every $6 \mathrm{~h}$ ) suppression test was carried out. Its results (Table 5) revealed initially elevated and then lowered serum values of DHEA-S ( 16.40 then $4.52 \mu \mathrm{mol} / \mathrm{L}), \mathrm{T}(3.84$ then $2.16 \mathrm{nmol} / \mathrm{L})$ and ANDR $(2.59$ then $1.78 \mathrm{ng} / \mathrm{mL}$ ). In the same series, a significantly elevated concentration of DHT $(578 \mathrm{pg} / \mathrm{mL})$ was observed and thereafter, upon dexamethasone, it returned to the reference range $(337 \mathrm{pg} / \mathrm{mL})$.

Table 5. Results of the three-day dexamethasone suppression test.

\begin{tabular}{|c|c|c|c|c|c|c|}
\hline & $\begin{array}{l}\text { ACTH }^{1} \\
(\mathrm{pg} / \mathrm{mL})\end{array}$ & $\begin{array}{c}\text { DHEA-S }^{2} \\
(\mu \mathrm{mol} / \mathrm{L})\end{array}$ & $\begin{array}{l}\text { ANDR }^{3} \\
(\mathrm{ng} / \mathrm{mL})\end{array}$ & $\begin{array}{c}\mathrm{T}^{4} \\
\text { (nmol/L) }\end{array}$ & $\begin{array}{c}\mathrm{DHT}^{5} \\
(\mathrm{pg} / \mathrm{mL})\end{array}$ & $\begin{array}{c}F^{6} \\
(\mathrm{ng} / \mathrm{mL})\end{array}$ \\
\hline $\begin{array}{l}\text { baseline } \\
\text { reference }\end{array}$ & $10.00-60.00$ & $3.17-14.39$ & $0.14-2.92$ & $0.38-2.74$ & $24.00-368.00$ & $37.00-194.00$ \\
\hline $\begin{array}{l}\text { values } \\
\text { baseline }\end{array}$ & 37.20 & 16.40 & 2.59 & 3.84 & 578.00 & 203.00 \\
\hline post-test & 0.90 & 4.52 & 1.78 & 2.16 & 337.00 & $<10.00$ \\
\hline
\end{tabular}

The abdominal ultrasound was also performed-no focal changes were found in the adrenal glands; both ovaries (LO: $33 \times 24 \times 21 \mathrm{~mm}$, RO: $35 \times 17 \times 16 \mathrm{~mm}$ ) were described as having normal solid/follicular architecture and the diameter of the largest follicle in the RO was $11 \mathrm{~mm}$. We have revisited FAI again (for SHBG, $105.0 \mathrm{nmol} / \mathrm{L}$ and T, $3.84 \mathrm{nmol} / \mathrm{L}$ ) and the result was 3.66, while T bioavailability $0.72 \mathrm{nmol} / \mathrm{L}$, i.e., $18.8 \%$. Hence, compared to previous estimations, FAI was slightly higher, however still within normal range.

Summarizing the patient's medical history and her current clinical and biochemical results, we concluded that there were no convincing arguments to establish the diagnosis of polycystic ovary syndrome (PCOS), especially because adrenal source of hyperandrogenism was beyond doubt. The patient was discharged with the diagnosis of mild late-onset $21 \alpha$-hydroxylase deficiency (steroid metabolites in urine) and hyperandrogenism due to enhanced "backdoor" androgen pathway. Furthermore, hormonal evaluation suggests a tendency for episodic stress-like reactions, manifested with higher ACTH and baseline cortisol concentrations close to the upper reference limit. However, $24 \mathrm{~h}$ urine cortisol excretion remained normal.

Our patient did not fulfill all standard criteria for PCOS diagnosis in adolescents [14-16]. She presented irregular menstruation, clinical hyperandrogenism; however, biochemical indices of testosterone excess, as well as insulin resistance were not permanent or significant, and ovaries did not present morphology typical for PCOS. Moreover, the patient's BMI was normal and stable. Nevertheless, an early stage of PCOS could not be totally excluded in the future besides the confirmed DHT excess of adrenal origin. Therefore, continued care of an endocrinologist-gynecologist was proposed, with the suggestion to start spironolactone treatment, combined with a two-component contraceptive pills comprising drospirenone for their antiandrogenic effects. A healthy lifestyle (diet, physical activity) was also advised as an essential method to avoid progression towards insulin resistance.

\section{Laboratory Methods}

The patient's BMI was based upon standard anthropometric measurements and calculated as weight $(\mathrm{kg}) /$ height $(\mathrm{m})$ squared. Insulin resistance (IR) was diagnosed according to the homeostasis model assessment for IR index (HOMA-IR), and the value was calculated using the following formula: (fasting plasma glucose $(\mathrm{mg} / \mathrm{dL}) / 18) \times$ fasting serum insulin $(\mu \mathrm{U} / \mathrm{mL}) / 22.5$. We accepted HOMA-IR $<2.5$ as proper score, between 2.5 and 4.0 as a borderline gray area and above 4.0 as evident IR [17,18]. 
All biochemical measurements were performed in laboratories of the university reference hospitals. In the gynecological ward insulin, prolactin and SHBG were measured by specific electro-chemiluminescence assays (automated Elecsys 2010 immunoanalyzer, Roche Diagnostics $\mathrm{GmbH})$. The same method, with the use of Cobas 6000 equipment and Roche reagents, was applied to measure total testosterone level. Free androgen index (FAI) was calculated as serum testosterone $(\mathrm{nmol} / \mathrm{L}) \times 100 / \mathrm{SHBG}(\mathrm{nmol} / \mathrm{L})$ ratio. The cut off value for FAI was 6.1 [19]. The chemiluminescence method was used to determine serum level of DHEA-S with the use of Immulite equipment and Siemens reagents. In the pediatric endocrinology ward, serum levels of DHEA-S, T, ANDR, 17OHP and C-peptide were evaluated by specific radioimmunoassay kits (automated Wallac Wizard 1470 Automatic Gamma Counter, Perkin Elmer). Insulin, cortisol, LH, FSH and E2 were measured by chemiluminescence method (Alinity i, Abbott). The standard colorimetric method was used for determination of glucose level (Clinical Chemistry Analyzer AU680, Beckman Coulter). Urinary profile of steroid metabolites was investigated in the reference laboratory (Laboratory of Steroid Hormones, The Children's Memorial Health Institute, Warsaw) by gas chromatography and mass spectrometry (GC-MS). Quantitative determination of serum DHT level was performed using an ELISA (enzyme-linked immunosorbent assay) kit (Demeditec Diagnostics GmbH, Kiel, Germany) and the absorbance was analyzed on Universal Microplate Reader (Elx800, BioTek Instruments, VT, USA).

\section{Discussion}

\subsection{Preliminary Suspicion of PCOS}

Initially, the studied adolescent with clinical symptoms of hyperandrogenism (severe acne, hirsutism, irregular menstruation) had been consulted by gynecologists. Based on their workup, insulin resistance was assumed and treatment with metformin was recommended, as the routine procedure in polycystic ovary syndrome. However, no documentation of characteristic ovaries' structure was available. Furthermore, glycemia and insulinemia in the course of OGTT were close to the upper borderline and HOMA-IR remained in the gray zone (a few months later all these measurements were clearly normal). Of note, total $\mathrm{T}$ and FAI were not elevated in contrast to evident clinical symptoms of hyperandrogenism. Serum DHEA-S and prolactin concentrations were only slightly above the upper reference limit. Altogether, PCOS has never been fully confirmed and eventually this suspicion was excluded a few months later, in the course of extended clinical investigation by pediatric endocrinologists.

\subsection{Early Diagnostics of CAH May Miss Its Non-Classic Forms}

The severity and clinical progression of CAH associated with $21 \alpha$-hydroxylase deficiency depends on the degree of the enzyme deficit. Traditionally, four forms of CAH are distinguished: classic form with or without loss of salt (salt-wasting or simple virilizing, respectively), non-classic form (late-onset form) and cryptogenic form (asymptomatic) [5,8]. In Poland a nationwide screening program for CAH, which covers the entire neonatal population, was launched in 2017 [20]. In the first stage of screening, on the $3 \mathrm{rd}$ or 4 th day of life, serum level of $17 \alpha \mathrm{OH}$-progesterone is determined. The reference range depends upon the week of pregnancy (hbd) at birth and on the day of life at blood collection. In the second stage of screening the steroid profile focused on $17 \alpha \mathrm{OH}$-progesterone, cortisol, 21-deoxycortisol, 11-deoxycortisol and androstenedione levels is determined in this same blood sample using liquid chromatography tandem mass spectrometry (LC/MS/MS). Still, this procedure does not provide unequivocal information about the risk of late-onset non-classic forms of $\mathrm{CAH}$ in the future. In some countries (Spain) there are attempts to also use pregnanetriolone estimation in urine samples collected on the 3rd day of life, using a piece of sorbent paper included in the screening kit to distinguish steroid profile characteristics for preterm infants from those with genuine $\mathrm{CAH}$ [21]. 


\subsection{Differential between Non-Classic CAH and PCOS}

Both PCOS and non-classic CAH are diseases manifesting in hyperandrogenism, which require careful differential diagnosis in adolescent girls and adult women [22]. In the present case, the first diagnostic steps routinely gravitated towards PCOS although this supposition was not fully supported by biochemical and ultrasonography (USG) studies. Subsequent investigations definitively excluded insulin resistance, did not detect changes in ovarian structure and hence focused on adrenal function. Serum T and DHEA-S fluctuated slightly at the upper limit of the reference range with maintained normal FAI and testosterone bioavailability. On the other hand, basal and Synacthen-stimulated cortisol, 17OHP and ANDR levels were not suggestive of late-onset congenital adrenal hyperplasia. Since CAH seemed doubtful, it was necessary to find an alternative source of androgen activity besides testosterone. DHT was the next potential candidate as a likely causative factor for skin symptoms [23,24]. Therefore, serum T and DHT were measured before and after 3-day dexamethasone suppression test. It appeared that basal DHT was almost twice the upper limit of the reference range while testosterone was only slightly elevated before the test. After ACTH suppression with dexamethasone, both androgens revealed significant decrease, which confirmed their predominantly adrenal origin. Moreover, in case of our patient, urinary steroid metabolites did not present a profile typical for polycystic ovary syndrome, characterized by elevated dehydroepiandrosterone, androstenediol and pregnenetriol [25]. As a matter of fact, the current case report is among just a few papers suggesting the relationship between diminished 21-hydroxylase activity and induction of the androgen backdoor pathway. Kamrath et al. [26] reported a retrospective analysis of steroid metabolites and their ratios in urine samples from a number of patients with 21-hydroxylase deficiency and found that androgen backdoor pathway contributed to hyperandrogenism. However, the studied cohort was comprised mainly of prepubertal individuals diagnosed with $\mathrm{CAH}$ in early infancy, therefore suffering from a more severe enzyme deficiency. Nonetheless, the authors hypothesized that this pathway might explain divergences between clinical degree of virilization and serum androgen levels, sometimes encountered in endocrine practice. Endocrinologists frequently meet adolescent girls or young women who are suffering with hirsutism, severe acne or both, while their diagnosis of non-classic $\mathrm{CAH}$ or PCOS is not fully confirmed [27].

\subsection{Subtle Alterations in Urine Steroid Profile}

At that stage, the major task appeared to be working out the mechanism of DHT generation, because it was not clear how to explain the discrepancy between changes in serum concentrations of two active androgens. The canonical androgen steroidogenesis proceeds from DHEA through androstenedione toward testosterone and finally, by way of $5 \alpha$-reduction, may lead to DHT, which is the most potent and irreversible end-stage metabolite [28]. In the discussed case, there were only slightly elevated serum DHEA-S, fluctuating T and normal ANDR, all not relevant for expected enhanced activity of this pathway, capable of inducing clinically serious hyperandrogenism. In the urinary steroid profile, only two metabolites were excreted at increased rate, $16 \alpha$-OHDHEA and PTN, while the remaining steroids presented normal excretion rates (Table 4). The 16 $\alpha$-OHDHEA was the only elevated DHEA-S metabolite, while four other DHEA-S derivatives (DHEA, 5-AND, An-3-ol, 5-PT) maintained normal $24 \mathrm{~h}$ excretion rate. Synthesis of $16 \alpha$-OHDHEA typically rises in the course of pregnancy as this DHEA metabolite derived from the placenta serves as a substrate for production of estriol. However, our patient was not pregnant at the time of the study. In the presented female adolescent, the selective increase of urinary $16 \alpha$-OHDHEA seems consequent to borderline elevation of circulating serum DHEA, a substrate for hepatic $16 \alpha$-hydroxylase. Actually, this constellation might be due to the postulated mild limitation of $21 \alpha$-hydroxylase activity, and in line with the observed increase in pregnanetriolone, the uniquely elevated metabolite of $17 \alpha \mathrm{OH}$-progesterone. The amounts and proportions of particular steroid metabolites in serum and urines may be dependent upon concentrations of their precursors and local enzymatic capacity in various tissues responsible for steroid metabolism (adrenals, liver, adipose tissue, etc.). Furthermore, the excretion of PTN was 
three-fold higher than the reference range, while the other four steroids derived from 17OHP (17-OHPN (5beta), 17-OHPN (5alpha), PT, PD) were excreted at a normal rate. We found it intriguing that only single metabolites of DHEA and 17OHP were elevated in $24 \mathrm{~h}$ urine collection of the investigated case. The urine excretion of androsterone and etiocholanolone remained normal in the presented case despite the presumed androsterone role as main intermediate in the backdoor pathway while etiocholanolone is associated rather with the classic pathway toward DHT. Former analyses revealed that later diagnosis of $\mathrm{CAH}$, i.e., presumably milder 21-hydroxylase deficiency, was associated with lower androstenedione to etiocholanolone ratios [26]. However, data from pre- and post-pubertal subjects were not analyzed separately, hence we cannot compare these results with findings from our patient. Furthermore, there is an alternative androgenic way from androstenedione via androstanedione to DHT with omission of androsterone and testosterone as well (Figure 1), which needs to be considered. This pathway employs $5 \alpha$-reductase type 1 (SRD5A1) and thereafter aldo-keto-reductases 1/4 (AKR1C1/4) with $17 \beta$-hydroxysteroid dehydrogenases 3/5 (HSD17B3/5) and might explain lack of elevated androsterone and etiocholanolone. Cortisol and cortisone as well as their metabolite ratios were also normal. It indicated, that there was no imbalance in activity of HSD11B1 and HSD11B2 (Figure 1) which could influence HPA axis and increased androgen production or could interfere with androgen metabolism. Therefore, eventually we had to solve the puzzle of severe clinical symptoms accompanied by only mild to moderate alterations of serum and urinary steroids.

\subsection{OHP Excess as Substrate for "Backdoor" Androgen Synthesis}

Increased secretion of intermediate steroids such as 17OHP and DHEA may suggest $21 \alpha$-hydroxylase deficiency with maintained normal efficiency of $11 \beta$-hydroxylase, although a moderate degree of biochemical disturbance suggests only mild enzymatic block, i.e., non-classic form of CAH. However, an impaired $21 \alpha$-hydroxylase activity, especially under stressful conditions, results in elevated $17 \mathrm{OHP}$, a substrate for $11 \beta$-hydroxylase type 1 , which converts it into 21 -deoxycortsol, a compound which in turn is metabolized by $11 \beta$-hydroxysteroid dehydrogenase type 2 (HSD11B2) into 21-deoxycortisone. Under the triple influence of $5 \beta$-reductase, $3 \alpha$-hydroxysteroid dehydrogenase and $20 \alpha$-hydroxysteroid dehydrogenase, 21-deoxycortisone is further transformed into PTN, the final urinary metabolite (Figure 1) $[12,26,29]$. One should bear in mind that PTN or its precursors cannot serve as substrates for androgen production because their generation proceeds via the $5 \beta$-reduction pathway and not through $5 \alpha$-reduction. Therefore, PTN is a marker of elevated $17 \mathrm{OHP}$ of adrenal origin only. On the other hand excess $17 \mathrm{OHP}$ can still supply $5 \alpha$-reduction shift toward the "backdoor" androgen formation $[11,12,30]$. We rather presumed the "backdoor" than the canonical pathway of androgen biosynthesis, because serum T oscillated within normal to high normal levels, while DHT was clearly pathologically elevated although remained reactive to adrenal suppression with dexamethasone. The androgen "backdoor" pathway relies on omission of testosterone on the way leading to DHT hence it seems highly probable that we had such a case to do with here [31]. The accumulation of $17 \mathrm{OHP}$ seems critical for both disorders- $\mathrm{CAH}$ and enhanced androgen backdoor pathway-as a result of 21-hydroxylase deficiency and as a substrate for the backdoor pathway, respectively. Even a mild/moderate increase of 17OHP may be sufficient to set in motion this steroidogenic route, leading to excess DHT via androsterone. In $\mathrm{CAH}$, this pathway could be parallel or even more potent, than the classic one, leading via androstenedione. On the other hand the androgen backdoor pathway may use some intermediate substrates from adrenals and finish synthesis of DHT locally in different tissues. This was observed in fetal life [30], in newborns [32] and in infants during mini-puberty [33] as well as in some pathologies like prostate cancer [34].

\subsection{Information from Steroid Metabolites' Ratios}

Taken together, limitation of $21 \alpha$-hydroxylase activity induces an androgen "backdoor" pathway supplying it with the main substrate, 17OHP [25,29]. In the presented case, there was a considerable increase in the urine metabolites of $17 \mathrm{OHP}$ (PTN $142.5 \mu \mathrm{g} / 24 \mathrm{~h}$; reference range 
10-50 $\mu \mathrm{g} / 24 \mathrm{~h}$ ) and DHEA (16 $\alpha$-OHDHEA $610.2 \mu \mathrm{g} / 24 \mathrm{~h}$; reference range 50-490 $\mu \mathrm{g} / 24 \mathrm{~h})$. Furthermore, as recommended by Kamrath et al., we performed calculations of steroid urine metabolite ratios to clarify the previous biochemical findings [26]. In our patient, the ratio of pregnanetriolone/cortisol metabolites (i.e., THF + aTHF + THE) of 0.045 was above the reference range, which supports diminished $21 \mathrm{OH}$-lase activity. In accordance, borderline values were found for two other ratios characteristic for $21 \alpha$-hydroxylase deficiency: pregnanetriol/cortisol metabolites (0.121) and $17 \alpha \mathrm{OH}$-pregnanolone/cortisol metabolites (0.039). Moreover, a substantially elevated value was observed for androsterone + etiocholanolone/cortisol metabolites (1.284), a feature which is postulated typical for diminished activity of $17 \beta \mathrm{OH}$-steroid dehydrogenase type 3 . This enzymatic deficiency impairs transformation of ANDR to $\mathrm{T}$, and can also corroborate the shift of androgen formation from canonical to "backdoor" androgen pathway through $5 \alpha$-androstanedione as an intermediate toward DHT (the alternative $\Delta-5$ pathway), by androsterone toward DHT (the "backdoor" pathway) or both. Our patient was an almost adult adolescent girl who presented the ratio of androsterone and etiocholanolone to tetrahydro-derivatives of cortisol and cortisone in urine, which may suggest diminished activity of HSD17B3 $[25,35]$. The meaning of such a ratio is difficult to explain, while the enzyme is involved in androgen production in different organs, e.g., gonads and peripheral tissues but not especially in adrenals.

\subsection{Study Limitation-Lack of 11-Oxygenated-19-Carbon Androgens Evaluation}

In our patient, the adrenal origin of DHT seemed evident and steroid metabolites in $24 \mathrm{~h}$ urine collection indicated increased adrenal 17OHP as a substrate for "backdoor" androgen pathway. Nevertheless, we realize that not all possible tests were done. We did not analyze the full spectrum of androgen steroids, which could influence the clinical status of our patient. According to recent reports, not only T and DHT are considered active androgens, but also 11-oxygenated-19-carbon (11oxC19) adrenal-derived steroids such as $11 \beta$-hydroxyandrostenedione (11-OHA4) and 11-ketoandrostenedione (11-KA4), 11ß-hydroxytestosterone (11-OHT) and 11-ketotestosterone (11-KT), or both may play a role and should be evaluated [36-39]. In this pathway 11 $\beta$-hydroxylase type 1 (CYP11B1) utilizing ANDR and T as substrates, produces 11-OHA4 and 11-OHT, respectively. Both of them are released into circulation and then can be activated in peripheral tissues by conversion with $11 \beta$-hydroxysteroid dehydrogenase type 2 (HSD11B2) into their 11-keto forms [40]. In our patient, we were not able to directly assess the concentration of 11 oxC19 steroids in the blood, but the correct values of their derivatives (11keto- as well as 11hydroxy- metabolites of androsterone and etiocholanolone) in daily urine collection seemed to rule out their excess. The activity of CYP11B1, HSD11B2 and HSD11B1 is of particular interest, as these enzymes used to be considered as engaged uniquely in glucocorticoid synthesis or metabolism, while it appears that they may be implicated in the androgen pathways too. Serum and local 11-oxygenated C19 steroids can be elevated in disorders of adrenal steroidogenesis as well as in the polycystic ovary syndrome, and in some instances both sources of their excess coexist $[37,41]$.

\subsection{Serum Levels vs. Paracrine and Intracrine Impact on Symptoms}

It is not uncommon that endocrinologists encounter trouble with the interpretation of serum androgens and urinary steroid profiles with respect to a patient's symptoms. We rarely can base interpretations on Aristotle's syllogism, because clinical effects usually depend upon several causative factors. The symptoms observed in our patient were due to the local action of androgens, e.g., testosterone and chiefly DHT, within the skin. However, our knowledge about the relationship between circulating DHT and its local action remains limited. Usually, we expect direct correlation between hormone concentration in blood and its presence near/inside the target cells, a classic endocrine paradigm, which holds true in most circumstances. On the other hand, especially with regard to androgens' action, paracrine and intracrine mechanisms should also be considered [42]. The example of prostate provides evidence of possible discrepancies between serum DHT levels and its intracrine 
production, and in consequence, the final DHT concentration within the gland. A similar situation is likely for pilosebaceous skin units. Excess DHT was found in our case; however, it does not mean that it was produced exclusively within the adrenals. Perhaps, progestin precursors were indeed of adrenal origin, while final steps of "backdoor" DHT biosynthesis took place in peripheral tissues, e.g., in the liver, fat tissue or both [43]. Furthermore, high circulating concentrations of DHT may potentially interfere with the hypothalamic-pituitary region and affect the natural rhythm for gonadotropin release. This could explain menstrual irregularities reported in the studied adolescent.

\subsection{Diagnostic Strategy}

Non-classic congenital adrenal hyperplasia may present with a wide spectrum of clinical manifestations from early adrenarche/pubarche in children with mild bone age acceleration up to secondary true precocious or early puberty with progressive hyperandrogenism through the adolescent period [44-47]. Symptoms of androgen excess are obviously easier to notice in affected girls than in boys. However, in adolescent girls there are frequent diagnostic dilemmas while trying to distinguish between hyperandrogenism due to the late-onset non-classic disorder of adrenal steroidogenesis, mild innate alterations in peripheral steroid metabolism, or early progression of PCOS, and sometimes a combination of these problems [22]. In all these conditions normal cortisol levels are maintained and no changes in electrolyte balance are usually detectable, although a tendency for slightly or temporarily elevated ACTH may be observed.

In the past, the diagnosis of $\mathrm{CAH}$ was routinely established based upon the analysis of serum steroid levels, focused specifically on $17 \mathrm{OHP}$ and androgens in relation to cortisol in response to $\mathrm{ACTH}_{1-24}$ stimulation test. A moderate raise of $17 \mathrm{OHP}$ used to be considered as confirmation for non-classic congenital adrenal hyperplasia [46]. Nevertheless, biochemical analyses relying either on blood tests or $24 \mathrm{~h}$ urine collections do not always allow drawing indubitable conclusions [48-50]. Interpretation of the urinary steroid profiles is complex and requires lots of experience. The collaborating laboratories are sometimes able to exclude $\mathrm{CAH}$ but do not provide any alternative diagnosis. Therefore, molecular analysis of the $21 \alpha$-hydroxylase gene, $C Y P 21 A 2$, seems the most sensible approach. However, the gene located on chromosome $6 \mathrm{p} 21.3$ is situated only $30 \mathrm{~kb}$ from a pseudogene, CYP21A1P, which shares $98 \%$ sequence similarity with CYP21A2 [51]. This feature renders the mutation analysis technically difficult, thus many laboratories use standardized predesigned multiplex ligation-dependent probe amplification (MLPA) assay, i.e., a panel of polymerase chain reaction (PCR) -based tests, which detect most large gene rearrangements (such as CYP21A2 deletions, 21A2/21A1P conversions) and several frequent gene mutations leading to serious impairment of enzymatic activity [52]. However, this method does not cover the variants typically responsible for non-classic CAH, e.g., P30L, V281L and P453S, associated with persisting $20-50 \%$ activity of $21 \alpha$-hydroxylase. Their detection requires expensive sequence analysis, which is rarely performed in routine clinical diagnostics of non-classic CAH. Nonetheless, in some instances, molecular analysis would be helpful to differentiate between CAH and PCOS [53]. Moreover, the risk of transmission of $\mathrm{CAH}$ to the next generation may be worth an extended genetic evaluation too. Accordingly, the option of genetic investigations and counseling was explained to the girl and her parents.

Overall, our experience with hyperandrogenism in childhood indicates a necessity for combined analysis of its potential adrenal and gonadal origin, preferably at the earliest age possible, when hormonal function of gonads does not yet interfere with diagnosis of precocious, exacerbated adrenarche, or both. Investigations should consider the timing of symptoms together with the results of blood testing, including stimulation as well as suppression exams of the adrenal function, and also relate them to the urine steroid metabolites excretion. The separate analyses are frequently not fully informative. In-depth investigations and searching for androgen precursors and metabolites in blood tests and urines seems to be a practical approach when an alternative pathway is taken into account. The evaluation of DHT level and confirmation of adrenal contribution in DHT synthesis is also of cardinal importance. 


\subsection{Treatment Options}

The general therapeutic aim in congenital adrenal hyperplasia is to supplement hormone deficiencies and to suppress excess synthesis of adrenal androgens. The pharmacological treatment of classic $\mathrm{CAH}$ relies upon chronic use of oral glucocorticoids. Hydrocortisone is conventionally considered as the first choice because its molecule is identical to endogenous cortisol; however, synthetic steroids such as prednisone or dexamethasone are also used in adult patients $[7,9,10,13]$. New therapeutic modalities based on modified release of hydrocortisone, capable of mimicking the normal diurnal profile of cortisol secretion and reducing early-morning ACTH surge and subsequent androgen production, have recently been developed [54]. Moreover, it appears that delayed-release hydrocortisone preparation exerts much improved control of alternative pathway-mediated androgen excess in patients suffering from $21 \alpha$-hydroxylase deficiency [13]. Unfortunately, these modern medications are not always available due to elevated costs. The therapy of salt-losing CAH should be enriched with mineralocorticoid receptor agonist, $9 \alpha$-fludrocortisone. In special situations (e.g., infection, injury, surgery and general anesthesia) the doses of glucocorticoids should be increased immediately, even 2-4 times, to prevent acute adrenal insufficiency (adrenal crisis). Adequate therapy determines the normal growth and development of the child. On the other hand, serious adverse effects, including iatrogenic Cushing's syndrome, may emerge if long-term steroid replacement becomes supraphysiological. For that reason permanent medical care and regular assessment of growth velocity, body weight and blood pressure, as well as biochemical control are recommended. In fully symptomatic cases of classic $\mathrm{CAH}$, girls with masculinization of the external genitalia additionally need surgical intervention, optimally in their infancy, with plausible re-evaluation later on, after puberty [7]. Despite the rigorous therapeutic regime for the classic forms of $\mathrm{CAH}$, patients with non-classic $\mathrm{CAH}$ and moderate hyperandrogenism are usually not treated at all, although potential risk of adrenal insufficiency in the acute stress may persist. In practice, the patients are notified that symptoms are inherent features of their individual appearance without major effects on their health. In females displaying menstrual irregularity, there is a tendency to over-diagnose the polycystic ovary syndrome and to introduce the typical therapeutic scheme for this disease. However, the coexistence of both disorders, i.e., non-classic CAH inducing androgen "backdoor" pathway in adrenals and PCOS with activation of the same ("backdoor") androgen steroidogenic pathway in ovaries should also be considered.

According to our investigations, the current case presents a very mild $21 \alpha$-hydroxylase deficiency (or heterozygous status) with consequent enhancement of the androgen "backdoor" pathway in adrenals, peripheral tissues or both, using adrenal origin precursors. Eventually, considering the patient's age, further control by an endocrinologist-gynecologist was recommended with suggested introduction of biphasic (estradiol/drospirenone) contraceptive pill to block the ovarian source of androgens, with concurrent low-dose spironolactone. Adrenal suppression (by glucocorticoid drugs) would be considered only in case of a lack of the anti-androgenic effects of the above-mentioned therapy or in the event of an exacerbation of symptoms. The patient was also given recommendations for dermatological care to control hirsutism and advice on healthy diet and regular physical activity to avoid the development of insulin resistance.

\section{Final Conclusions}

We believe that diagnosis of PCOS in adolescent girls and young women should be established very carefully, taking into account innate disorders of adrenal steroidogenesis as a coexisting parallel problem, or as the main disease. The diagnostic procedure is not straightforward, usually takes time and requires several stages to collect data from basal analyses and functional tests, with estimation of serum steroids and their urinary metabolites. However, even evident clinical symptoms are not always in direct correlation with biochemical findings. Even mild limitation of $21 \alpha$-hydroxylase activity in course of non-classic CAH is sufficient to shift adrenal androgen steroidogenesis toward the alternative "backdoor" pathway, which can be also be achieved outside the adrenal cortex. Therefore, paracrine 
and intracrine processes leading to active androgen biosynthesis in peripheral and target tissues should be considered in diagnosis. The analysis of urinary steroid metabolites is helpful because it reflects the status of several pathways of steroidogenesis as well as steroid peripheral metabolism by a single cross-sectional study.

Taken together, it is essential to emphasize that diagnostics of hyperandrogenism in girls/women cannot be limited to crude estimation of total or free testosterone levels, which can be normal. Circulating DHT levels and also the androgen backdoor pathway of its synthesis should be considered equally. This approach may provide more precise data as steroid metabolites might suggest not only confirmation or exclusion of $\mathrm{CAH}$, but sometimes also explain more complex steroidogenic and metabolic traces.

Author Contributions: Conceptualization, M.S. and M.F.; patient care and data collection, M.S., K.B.-G. and D.W.; visualization, M.S. and M.F.; methodology and data analysis, M.F. and M.S., writing—original draft, M.S., writing-review and editing, M.F. The datasets used, analyzed or both, during the current study are available from the correspondence author* on request. All authors have read and agreed to the published version of the manuscript.

Funding: This research was funded by Poznan University of Medical Sciences devoted for Department of Pediatric Diabetes and Obesity.

Conflicts of Interest: The authors declare no conflict of interest. The funders had no role in the design of the study; in the collection, analyses, or interpretation of data; in the writing of the manuscript, or in the decision to publish the results.

\section{References}

1. Jacobson, L. Hypothalamic-pituitary-adrenocortical axis regulation. Endocrinol. Metab. Clin. N. Am. 2005, 34, 271-292. [CrossRef] [PubMed]

2. Bornstein, S.R.; Ehrhart-Bornstein, M. Basic and clinical aspects of intraadrenal regulation of steroidogenesis. Z Für. Rheumatol. 2000, 59, II12-II17. [CrossRef]

3. Einer-Jensen, N.; Carter, A.M. Local transfer of hormones between blood vessels within the adrenal gland may explain the functional interaction between the adrenal cortex and medulla. Med. Hypotheses. 1995, 44, 471-474. [CrossRef]

4. White, P.C.; Speiser, P.W. Congenital adrenal hyperplasia due to 21-hydroxylase deficiency. Endocr. Rev. 2000, 21, 245-291. [CrossRef] [PubMed]

5. Nimkarn, S.; Lin-Su, K.; New, M.I. Steroid 21-hydroxylase deficiency congenital adrenal hyperplasia. Pediatr. Clin. N. Am. 2011, 58, 1281-1300. [CrossRef]

6. Nimkarn, S.; New, M.I. Steroid 11ß-hydroxylase deficiency congenital adrenal hyperplasia. Trends Endocrinol. Metab. 2008, 19, 96-99. [CrossRef]

7. Speiser, P.W.; Arlt, W.; Auchus, R.J.; Baskin, L.S.; Conway, G.S.; Merke, D.P.; Meyer-Bahlburg, H.F.; Miller, W.L.; Murad, M.H.; Oberfield, S.E.; et al. Congenital adrenal hyperplasia due to steroid 21-hydroxylase deficiency: An Endocrine Society Clinical Practice Guideline. J. Clin. Endocrinol. Metab. 2018, 103, 4043-4088. [CrossRef]

8. Migeon, C.J.; Wisniewski, A.B. Congenital adrenal hyperplasia owing to 21-hydroxylase deficiency: Growth, development, and therapeutic considerations. Endocrinol. Metab. Clin. N. Am. 2001, 30, 193-206. [CrossRef]

9. Charmandari, E.; Chrousos, G.; Merke, D.P. Classic congenital adrenal hyperplasia. In Adrenal Glands: Diagnostic Aspects and Surgical Therapy; Springer: Berlin/Heidelberg, Germany, 2005; p. 107.

10. Kim, M.S.; Ryabets-Lienhard, A.; Geffner, M.E. Management of congenital adrenal hyperplasia in childhood. Curr. Opin. Endocrinol. Diabetes. Obes. 2012, 19, 483-488. [CrossRef]

11. Gupta, M.K.; Guryev, O.L.; Auchus, R.J. 5alpha-reduced C21 steroids are substrates for human cytochrome P450c17. Arch. Biochem. Biophys. 2003, 418, 151-160. [CrossRef]

12. Homma, K.; Hasegawa, T.; Nagai, T.; Adachi, M.; Horikawa, R.; Fujiwara, I.; Tajima, T.; Takeda, R.; Fukami, M.; Ogata, T. Urine steroid hormone profile analysis in cytochrome P450 oxidoreductase deficiency: Implication for the backdoor pathway to dihydrotestosterone. J. Clin. Endocrinol. Metab. 2006, 91, 2643-2649. [CrossRef] [PubMed] 
13. Jones, C.M.; Mallappa, A.; Reisch, N.; Nikolaou, N.; Krone, N.; Hughes, B.A.; O'Neil, D.M.; Whitaker, M.J.; Tomlinson, J.W.; Storbeck, K.H.; et al. Modified-release and conventional glucocorticoids and diurnal androgen excretion in congenital adrenal hyperplasia. J. Clin. Endocrinol. Metab. 2017, 102, 1797-1806. [CrossRef] [PubMed]

14. Chang, J.; Azziz, R.; Legro, R.; Dewailly, D.; Franks, S.; Tarlatzis, B.; Fauser, B. The Rotterdam ESHRE/ASRM-Sponsored PCOS Consensus Workshop Group. Revised 2003 consensus on diagnostic criteria and long-term health risks related to polycystic ovary syndrome. Fertil. Steril. 2004, 81, 19-25.

15. Ibáñez, L.; Oberfield, S.E.; Witchel, S.; Auchus, R.J.; Chang, R.J.; Codner, E.; Dabadghao, P.; Darendeliler, F.; Elbarbary, N.S.; Gambineri, A.; et al. An international consortium update: Pathophysiology, diagnosis, and treatment of polycystic ovarian syndrome in adolescence. Horm. Res. Paediatr. 2017, 88, 371-395. [CrossRef]

16. Gambineri, A.; Fanelli, F.; Prontera, O.; Repaci, A.; Di Dalmazi, G.; Zanotti, L.; Pagotto, U.; Flacco, M.E.; Guidi, J.; Fava, G.A.; et al. Prevalence of hyperandrogenic states in late adolescent and young women: Epidemiological survey on italian high-school students. J. Clin. Endocrinol. Metab. 2013, 98, 1641-1650. [CrossRef]

17. Kurtoğlu, S.; Hatipoğlu, N.; Mazıcıoğlu, M.; Kendirici, M.; Keskin, M.; Kondolot, M. Insulin resistance in obese children and adolescents: HOMA-IR cut-off levels in the prepubertal and pubertal periods. J. Clin. Res. Pediatr. Endocrinol. 2010, 2, 100-106. [CrossRef]

18. Singh, Y.; Garg, M.K.; Tandon, N.; Marwaha, R.K. A study of insulin resistance by HOMA-IR and its cut-off value to identify metabolic syndrome in urban Indian adolescents. J. Clin. Res. Pediatr. Endocrinol. 2013, 5, $245-251$.

19. Zhou, Z.; Ni, R.; Hong, Y.; Li, Y.; Wang, Y.; Zhao, X.; Yang, D. Defining hyperandrogenaemia according to the free androgen index in Chinese women: A cross-sectional study. Clin. Endocrinol. 2012, 77, 446-452. [CrossRef]

20. Ginalska-Malinowska, M. Classic congenital adrenal hyperplasia due to 21-hydroxylase deficiency-The next disease included in the neonatal screening program in Poland. Dev. Period. Med. 2018, 22, 197-200.

21. Alonso-Fernández, J.R. Pregnanetriolone in paper-borne urine for neonatal screening for 21-hydroxylase deficiency: The place of urine in neonatal screening. Mol. Genet. Metab. Rep. 2016, 8, 99-102. [CrossRef]

22. Azziz, R.; Sanchez, L.A.; Knochenhauer, E.S.; Moran, C.; Lazenby, J.; Stephens, K.C.; Taylor, K.; Boots, L.R. Androgen excess in women: Experience with over 1000 consecutive patients. J. Clin. Endocrinol. Metab. 2004, 89, 453-462. [CrossRef] [PubMed]

23. Marchetti, P.M.; Barth, J.H. Clinical biochemistry of dihydrotestosterone. Ann. Clin. Biochem. 2013, 50, 95-107. [CrossRef] [PubMed]

24. Swerdloff, R.S.; Dudley, R.E.; Page, S.T.; Wang, C.; Salameh, W.A. Dihydrotestosterone: Biochemistry, physiology, and clinical implications of elevated blood levels. Endocr. Rev. 2017, 38, 220-254. [CrossRef] [PubMed]

25. Dhayat, N.A.; Marti, N.; Kollmann, Z.; Troendle, A.; Bally, L.; Escher, G.; Grössl, M.; Ackermann, D.; Ponte, B.; Pruijm, M.; et al. Members of the SKIPOGH Study Group. Urinary steroid profiling in women hints at a diagnostic signature of the polycystic ovary syndrome: A pilot study considering neglected steroid metabolites. PLoS ONE 2018, 13, e0203903. [CrossRef]

26. Kamrath, C.; Hochberg, Z.; Hartmann, M.F.; Remer, T.; Wudy, S.A. Increased activation of the alternative "backdoor" pathway in patients with 21-hydroxylase deficiency: Evidence from urinary steroid hormone analysis. J. Clin. Endocrinol. Metab. 2012, 97, 367-375. [CrossRef]

27. Skordis, N.; Shammas, C.; Phedonos, A.A.P.; Kyriakou, A.; Toumba, M.; Neocleous, V.; Phylactou, L.A. Genetic defects of the CYP21A2 gene in girls with premature adrenarche. J. Endocrinol. Investig. 2015, 38, 535-539. [CrossRef]

28. Miller, W.L.; Auchus, R.J. The molecular biology, biochemistry, and physiology of human steroidogenesis and its disorders. Endocr. Rev. 2011, 32, 81-151. [CrossRef]

29. Cox, R.I.; Finkelstein, M. Pregnane- $3 \alpha, 17 \alpha, 20 \alpha$-Triol and Pregnane- $3 \alpha, 17 \alpha, 20 \alpha$-Triol-11-one excretion by patients with adrenocortical dysfunction. J. Clin. Investig. 1957, 36, 1726-1735. [CrossRef]

30. O'Shaughnessy, P.J.; Antignac, J.P.; Le Bizec, B.; Morvan, M.-L.; Svechnikov, K.; Söder, O.; Savchuk, L.; Monteiro, A.; Soffientini, U.; Johnston, Z.C.; et al. Alternative (backdoor) androgen production and masculinization in the human fetus. PLoS Biol. 2019, 17, e3000002.

31. Auchus, R.J. The backdoor pathway to dihydrotestosterone. Trends Endocrinol. Metab. TEM 2004, 15, 432-438. [CrossRef] 
32. Christakoudi, S.; Cowan, D.A.; Christakudis, G.; Taylor, N.F. 21-hydroxylase deficiency in the neonate-Trends in steroid anabolism and catabolism during the first weeks of life. J. Steroid. Biochem. Mol. Biol. 2013, 138, 334-347. [CrossRef] [PubMed]

33. Dhayat, N.A.; Dick, B.; Frey, B.M.; d'Uscio, C.H.; Vogt, B.; Flück, C.E. Androgen biosynthesis during minipuberty favors the backdoor pathway over the classic pathway: Insights into enzyme activities and steroid fluxes in healthy infants during the first year of life from the urinary steroid metabolome. J. Steroid. Biochem. Mol. Biol. 2017, 165, 312-322. [CrossRef] [PubMed]

34. Fiandalo, M.V.; John Wilton, J.; Mohler, J.L. Roles for the backdoor pathway of androgen metabolism in prostate cancer response to castration and drug treatment. Int. J. Biol. Sci. 2014, 10, 596-601. [CrossRef] [PubMed]

35. Krone, N.; Hughes, B.A.; Lavery, G.G.; Stewart, P.M.; Arlt, W.; Shackleton, C.H.L. Gas chromatography/mass spectrometry (GC/MS) remains a pre-eminent discovery tool in clinical steroid investigations even in the era of fast liquid chromatography tandem mass spectrometry (LC/MS/MS). J. Steroid. Biochem. Mol. Biol. 2010, 121, 496-504. [CrossRef]

36. Turcu, A.F.; Nanba, A.T.; Chomic, R.; Upadhyay, S.K.; Giordano, T.J.; Shields, J.J.; Merke, D.P.; Rainey, W.E.; Auchus, R.J. Adrenal-derived 11-oxygenated 19-carbon steroids are the dominant androgens in classic 21-hydroxylase deficiency. Eur. J. Endocrinol. 2016, 174, 601-609. [CrossRef]

37. O’Reilly, M.W.; Kempegowda, P.; Jenkinson, C.; Taylor, A.E.; Quanson, J.L.; Storbeck, K.H.; Arlt, W. 11-Oxygenated C19 steroids are the predominant androgens in polycystic ovary syndrome. J. Clin. Endocrinol. Metab. 2017, 102, 840-848. [CrossRef]

38. Rege, J.; Turcu, A.F.; Kasa-Vubu, J.Z.; Lerario, A.M.; Auchus, G.C.; Auchus, R.J.; Smith, J.M.; White, P.C.; Rainey, W.E. 11-ketotestosterone is the dominant circulating bioactive androgen during normal and premature adrenarche. J. Clin. Endocrinol. Metab. 2018, 103, 4589-4598. [CrossRef]

39. Turcu, A.F.; Auchus, R.J. Clinical significance of 11-oxygenated androgens. Curr. Opin. Endocrinol. Diabetes Obes. 2017, 24, 252-259. [CrossRef]

40. Turcu, A.F.; Rege, J.; Auchus, R.J.; Rainey, W.E. 11-Oxygenated androgens in health and disease. Nat. Rev. Endocrinol. 2020, 16, 284-296. [CrossRef]

41. Azziz, R.; Black, V.; Hines, G.A.; Fox, L.M.; Boots, L.R. Adrenal androgen excess in the polycystic ovary syndrome: Sensitivity and responsivity of the hypothalamic-pituitary-adrenal axis. J. Clin. Endocrinol. Metab. 1998, 83, 2317-2323. [CrossRef]

42. Labrie, F.; Luu-The, V.; Labrie, C.; Bélanger, A.; Simard, J.; Lin, S.X.; Pelletier, G. Endocrine and intracrine sources of androgens in women: Inhibition of breast cancer and other roles of androgens and their precursor dehydroepiandrosterone. Endocr. Rev. 2003, 24, 152-182. [CrossRef] [PubMed]

43. Schiffer, L.; Arlt, W.; Storbeck, K.H. Intracrine androgen biosynthesis, metabolism and action revisited. Mol. Cell Endocrinol. 2018, 465, 4-26. [CrossRef] [PubMed]

44. Livadas, S.; Dracopoulou, M.; Dastamani, A.; Sertedaki, A.; Maniati-Christidi, M.; Magiakou, A.M.; Kanaka-Gantenbein, C.; Chrousos, G.P.; Dacou-Voutetakis, C. The spectrum of clinical, hormonal and molecular findings in 280 individuals with nonclassical congenital adrenal hyperplasia caused by mutations of the CYP21A2 gene. Clin. Endocrinol. 2015, 82, 543-549. [CrossRef] [PubMed]

45. Livadas, S.; Bothou, C. Management of the female with non-classical congenital adrenal hyperplasia (NCCAH): A patient-oriented approach. Front. Endocrinol. 2019, 10, 366. [CrossRef] [PubMed]

46. Kurtoğlu, S.; Hatipoğlu, N. Non-classical congenital adrenal hyperplasia in childhood. J. Clin. Res. Pediatr. Endocrinol. 2017, 9, 1-7. [CrossRef]

47. Accetta, S.G.; Di Domênico, K.; Ritter, C.G.; Ritter, A.T.; Capp, E.; Spritzer, P.M. Anthropometric and endocrine features in girls with isolated premature pubarche or non-classical congenital adrenal hyperplasia. J. Pediatr. Endocrinol. Metab. 2004, 17, 767-773. [CrossRef]

48. Lucas-Herald, A.K.; Rodie, M.; Lucaccioni, L.; Shapiro, D.; McNeilly, J.; Shaikh, M.G.; Ahmed, S.F. The pitfalls associated with urinary steroid metabolite ratios in children undergoing investigations for suspected disorders of steroid synthesis. Int. J. Pediatr. Endocrinol. 2015, 2015, 10. [CrossRef]

49. Ambroziak, U.; Kępczyńska-Nyk, A.; Kuryłowicz, A.; Małunowicz, E.M.; Wójcicka, A.; Miśkiewicz, P.; Macech, M. The diagnosis of nonclassic congenital adrenal hyperplasia due to 21-hydroxylase deficiency, based on serum basal or post-ACTH stimulation 17-hydroxyprogesterone, can lead to false-positive diagnosis. Clin. Endocrinol. 2016, 84, 23-29. [CrossRef] 
50. Török, D.; Halász, Z.; Garami, M.; Homoki, J.; Fekete, G.; Sólyom, J. Limited value of serum steroid measurements in identification of mild form of 21-hydroxylase deficiency. Exp. Clin. Endocrinol. Diabetes Off. J. Ger. Soc. Endocrinol. Ger. Diabetes Assoc. 2003, 111, 27-32. [CrossRef]

51. Krone, N.; Arlt, W. Genetics of congenital adrenal hyperplasia. Best Pract. Res. Clin. Endocrinol. Metab. 2009, 23, 181-192. [CrossRef]

52. Pignatelli, D.; Carvalho, B.L.; Palmeiro, A.; Barros, A.; Guerreiro, S.G.; Macut, D. The complexities in genotyping of congenital adrenal hyperplasia: 21-hydroxylase deficiency. Front. Endocrinol. 2019, 10, 1-17. [CrossRef] [PubMed]

53. Pall, M.; Azziz, R.; Beires, J.; Pignatelli, D. The phenotype of hirsute women: A comparison of polycystic ovary syndrome and 21-hydroxylase-deficient nonclassic adrenal hyperplasia. Fertil. Steril. 2010, 94, 684-689. [CrossRef] [PubMed]

54. Whitaker, M.; Debono, M.; Huatan, H.; Merke, D.; Arlt, W.; Ross, R.J. An oral multiparticulate, modified-release, hydrocortisone replacement therapy that provides physiological cortisol exposure. Clin. Endocrinol. 2014, 80, 554-561. [CrossRef] [PubMed]

(C) 2020 by the authors. Licensee MDPI, Basel, Switzerland. This article is an open access article distributed under the terms and conditions of the Creative Commons Attribution (CC BY) license (http://creativecommons.org/licenses/by/4.0/). 